\title{
EFEITOS AMBIENTAIS E GENÉTICOS SOBRE ESCORES VISUAIS E GANHO EM PESO AO SOBREANO DE BOVINOS BRANGUS
}

\author{
GENETIC AND ENVIRONMENTAL AFFECTS ON VISUAL SCORES AND YEARLING \\ WEIGHT GAIN OF BRANGUS CATTLE
}

\author{
Queiroz, S.A. ${ }^{\text {; }}$ Oliveira, J.A. ${ }^{2}$; Costa, G.Z. ${ }^{3}$ e Fries, L.A. ${ }^{4 \dagger}$ \\ 'Departamento de Zootecnia. Faculdade de Ciências Agrárias e Veterinária. UNESP. Jaboticabal, SP. Brasil. \\ saquei@fcav.unesp.br \\ ${ }^{2}$ Departamento de Ciências Exatas. Faculdade de Ciências Agrárias e Veterinária. UNESP. Jaboticabal, \\ SP. Brasil. jaoliv@fcav.unesp.br \\ 33gabizcosta@yahoo.com.br \\ ${ }^{4}$ GenSys Consultores Associados S/C Ltda. Jaboticabal, SP. Brasil.
}

\section{Palavras chave adicionais}

Conformação. Heterozigose. Idade da vaca ao parto. Idade do animal ao sobreano. Musculatura. Precocidade.

\section{RESUMO}

O objetivo do presente trabalho foi estudar os efeitos da idade da vaca ao parto (IVP) e idade do animal ao sobreano (IDS), bem como os efeitos genéticos aditivos diretos (AD) e maternos (AM) e da heterozigose individual $(\mathrm{HI})$, sobre os escores visuais de conformação (CS), precocidade (PS) e musculatura (MS) ao sobreano e o ganho médio diário de peso da desmama ao sobreano (GDS) de animais formadores da raça Brangus. Foram analisados $24531,21166,24006$ e 25419 dados de CS, PS, MS e GDS, respectivamente, de animais nascidos entre 1986 e 2002, provenientes do arquivo zootécnico da empresa Gensys Consultores Associados S/C Ltda. As análises foram realizadas pela metodologia de quadrados mínimos utilizando modelos que incluíram os efeitos de grupo de contemporâneos como variável classificatória e IVP, IDS, AD, AM e HI como covariáveis. IVP apresentou efeitos linear $e$ quadrático $(p<0,01)$ sobre GDS e linear $(p<0,01)$ para PS, enquanto que o efeito quadrático da IDS não foi significativo para PS e GDS. AD e AM foram significativos $(p<0,01)$ somente para os escores PS e MS, respectivamente. Todas as características avaliadas foram influenciadas significativa-

$\dagger$ In memorian.

\section{ADDITIONAL KEYWORDS}

Age of animal at yearling. Age of cow at calving. Conformation. Heterozygosity. Musculature. Precocity.

mente $(p<0,01)$ pelo efeito da heterozigose individual. Os efeitos ambientais e genéticos revelaramse importantes fontes de variação para as características estudadas, devendo-se, pois, serem levados em consideração em tais casos, na distinção e comparação dos animais para fins de seleção.

\section{SUMMARY}

This research aimed at studying the effects of age of the cow at calving (IVP), age of the animal at yearling (IDS), the direct additive genetic (AD) and maternal (AM) effects and individual heterozygosity (HI) on visual scores of conformation (CS), early finishing (PS) and muscling (MS) at postweaning and average daily gain from weaning to yearling (GDS) of cattle used to originate the Brangus breed. There were analyzed records on 24 531, 21 166, 24006 and 25419 for CS, PS, MS and GDS, respectively, of animals born from 1986 to 2002 belonging to livestock files of Gensys Consultores Associados S/C Ltda. The analyses were performed by the least square method using mathematical models that included contemporary group as class variable and IVP, IDS, AD, AM and HI as covariates. IVP 


\section{QUEIROZ, OLIVEIRA, COSTA EFRIES}

showed linear and quadratic effects $(p<0.01)$ on GDS and linear $(p<0.01)$ on PS, while the quadratic effect of IDS was not significant for PS and GDS. $A D$ and $A M$ were significant $(p<0.01)$ only for $P S$ and MS scores, respectively. All the traits were significantly $(p<0.01)$ influenced by HI. The environmental and genetic effects were important sources of variation for the studied traits and should be taken into account when comparison of animals and selection were performed.

\section{INTRODUÇÃO}

O melhoramento genético de bovinos no Brasil tem sido apoiado, principalmente, na seleção tendo como base pesos padronizados em diferentes idades e ganhos de peso. Como complemento às medidas de crescimento, programas de melhoramento genético têm adotado medidas de avaliação visual por escores de conformação (C), precocidade $(\mathrm{P})$ e musculatura $(\mathrm{M})$. A adição dessas medidas traz como vantagens, o baixo custo de implantação do sistema de mensurações e a possibilidade de avaliar características ligadas à composição do peso dos animais (Campos e Cardoso, 1995; Fries, 1996).

As avaliações por escores visuais são consideradas como uma forma para se identificar animais de melhor conformação produtiva e tentar predizer as medidas que seriam obtidas no momento em que forem abatidos. Na avaliação de precocidade tentase predizer a capacidade do animal chegar a um grau de acabamento mínimo de carcaça com peso vivo não elevado. Para musculatura, avalia-se o desenvolvimento muscular do animal como um todo (Costa et al., 2008).

A expressão das características fenotípicas do indivíduo é resultado da ação de seus genes, dos efeitos ambientais e suas interações. Existem influências de fatores genéticos e de ambiente sobre as características definidas no objetivo de seleção e o conhecimento desses fatores é de suma importância para que se possa comparar e identificar os animais mais produtivos (Bocchi et al., 2004).
O gado Brangus é uma raça sintética, formada por animais com composição $5 / 8$ Aberdeen Angus e 3/8 Zebu. As primeiras experiências que resultaram no Brangus foram realizadas a partir 1912, no estado norte-americano de Louisiana. O objetivo era a criação de um animal que apresentasse altos índices de produtividade mesmo criado em condições de clima e meio-ambiente adversas, típicas das regiões tropicais e subtropicais (Maciel, 2000).

No Brasil, trabalho similar de cruzamento, utilizando as raças Angus e Nelore, foi desenvolvido por técnicos do Ministério da Agricultura, em Bagé (RS), na década de 40, resultando na raça Ibagé, assim denominada pelos técnicos na época. Alguns anos depois, em função do cruzamento ser o mesmo alcançado nos Estados Unidos, o nome da raça passou a ser Brangus Ibagé, até que se tornou apenas Brangus, anos mais tarde (Maciel, 2000).

Nos últimos anos, a raça Brangus teve grande participação na bovinocultura brasileira, sendo que entre 1998 a 2002 houve um aumento da ordem de $448 \%$ no número de animais registrados e de $15,7 \%$ entre os anos de 2008 e 2009, totalizando neste último ano 9248 registros (Associação Brasileira de Criadores de Zebu, 2011), além de mostrar de 2009 a 2010 um crescimento de 73,6\% na venda de sêmen (ANUALPEC, 2010). Assim, a raça Brangus apresenta-se hoje como um importante recurso genético para a produção de carne no país. Apesar disso, poucos são os estudos efetuados com essa raça, com o intuito de subsidiar a elaboração de diretrizes aos seus programas de melhoramento.

O presente trabalho teve como objetivo verificar se os efeitos da idade da vaca ao parto e idade do animal ao sobreano, bem como os efeitos genéticos aditivos diretos e maternos e da heterozigose individual, influenciam os escores visuais de conformação, precocidade e musculatura ao sobreano e ganho médio diário de peso da desmama ao sobreano de animais formadores 
da raça Brangus, no Brasil.

\section{MATERIALEMÉTODOS}

Os dados utilizados neste estudo foram provenientes do arquivo zootécnico da empresa Gensys Consultores Associados S/C Ltda, relativo às raças Brangus e Angus de 110 rebanhos comerciais criados nas regiões Sul, Centro-Oeste e Sudeste do Brasil. Os referidos dados correspondem a observações de conformação (CS), precocidade (PS) e musculatura (MS) ao sobreano e do ganho médio diário de peso da desmama ao sobreano (GDS) de animais formadores da raça Brangus, nascidos no período de 1986 a 2002, em todos os meses do ano.

As notas dos escores de CS, PS e MS foram dadas a cada animal, seguindo metodologia que avalia os animais em relação ao grupo de contemporâneos. As notas foram atribuídas por um técnico treinado, e variaram de 1 a 5 , sendo 5 a melhor expressão da característica (Costa $e t$ al., 2008).

A partir do arquivo original dos animais da raça Brangus foram eliminadas informações incompletas e valores incoerentes biologicamente. Assim, o arquivo passou a contar com 24 531, 21 166, 24006 e 25419 observações de CS, PS, MS e GDS, respectivamente, além da identificação do animal, touro, vaca, frações Nelore do animal, do pai, da mãe, da avó materna e do avô materno, sexo, pesos a desmama e ao sobreano, idade da vaca ao parto, idade do animal ao sobreano, época de nascimento, heterozigoses individual e materna e grupo de contemporâneos.

Os valores para a heterozigose individual (HI) foram calculados conforme Teixeira e Albuquerque (2003) como:

$\mathrm{HI}=$ raça do pai + raça da mãe $-2 \times$ (raça do pai $x$ raça da mãe)

em que:

raça= fração zebuína do indivíduo.
A heterozigose materna não foi considerada neste estudo, dado que foram utilizadas apenas vacas puras como mães, tanto Nelore como Angus.

O ganho médio diário até a desmama (GDS) foi calculado pela razão da diferença entre o peso observado ao sobreano e a desmama e o número de dias entre as datas de sobreano e da desmama.

O grupo de contemporâneos foi composto por animais do mesmo sexo, grupo de manejo de desmama, mesma fazenda, época, dia, mês e ano de nascimento, além de mesma fazenda e grupo de manejo de sobreano. Grupos de contemporâneos contendo menos que cinco animais foram eliminados, bem como touros com menos de cinco filhos.

A idade da vaca ao parto (IVP) variou de 2 a 15 anos e, apesar de que o número de fêmeas Nelore tenha sido maior, a distribuição de fêmeas nas classes de idade foi proporcional tanto nesta raça como na Angus. A variável época do nascimento foi definida em termos de quatro períodos de três meses, a partir de janeiro.

Os efeitos genéticos aditivos diretos e maternos foram definidos como a fração zebuína do bezerro e da mãe, respectivamente (tabela I).

Os efeitos de ambientes e genéticos sobre os escores visuais e ganho médio diário de peso da desmama ao sobreano (GDS) foram analisados pelo método dos quadrados mínimos, por meio do procedimento GLM (SAS 9.1, Institute, Cary, North Carolina, USA). O modelo geral proposto foi:

$$
Y=X \beta+e
$$

em que:

$\mathrm{Y}=$ vetor das variáveis dependentes (CS, PS, MS e GDS);

$X=$ matriz de incidência de efeitos fixos para as variáveis dependentes;

$\beta=$ vetor dos efeitos fixos;

$\mathrm{e}=$ vetor de efeitos residuais aleatórios.

Os efeitos fixos considerados foram: 


\section{QUEIROZ, OLIVEIRA, COSTA E FRIES}

Tabela I. Constituição dos grupos genéticos e definição dos efeitos genéticos aditivos diretos e maternos de bovinos formadores da raça Brangus. (Constitution of the genetic groups and definition of the additive genetic direct and maternal effects for bovines forming Brangus cattle).

\begin{tabular}{|c|c|c|c|c|c|c|c|}
\hline \multirow{3}{*}{ Touro } & \multirow{3}{*}{ Vaca } & \multirow{3}{*}{ Bezerro } & \multirow{3}{*}{ Número de bezerros } & \multicolumn{4}{|c|}{ Efeito aditivo } \\
\hline & & & & \multicolumn{2}{|c|}{ Direto } & \multicolumn{2}{|c|}{ Materno } \\
\hline & & & & $\mathrm{N}$ & A & $\mathrm{N}$ & A \\
\hline $\mathrm{N}$ & $\mathrm{N}$ & $\mathrm{N}$ & 119 & 1 & 0 & 1 & 0 \\
\hline$A$ & $\mathrm{~N}$ & $1 \mathrm{~N} 1 \mathrm{~A}$ & 19130 & $1 / 2$ & $1 / 2$ & 1 & 0 \\
\hline $\mathrm{N}$ & A & $1 \mathrm{~N} 1 \mathrm{~A}$ & 36 & $1 / 2$ & $1 / 2$ & 0 & 1 \\
\hline $1 \mathrm{~N} 1 \mathrm{~A}$ & $\mathrm{~N}$ & $3 N 1 A$ & 1002 & $3 / 4$ & $1 / 4$ & 1 & 0 \\
\hline $3 N 1 A$ & $A$ & $3 N 5 A$ & 7265 & $3 / 8$ & $5 / 8$ & 0 & 1 \\
\hline $1 \mathrm{~N} 3 \mathrm{~A}$ & $\mathrm{~N}$ & $5 N 3 A$ & 26 & $5 / 8$ & $3 / 8$ & 1 & 0 \\
\hline $3 N 1 A$ & $\mathrm{~N}$ & $7 N 1 A$ & 41 & $7 / 8$ & $1 / 8$ & 1 & 0 \\
\hline $3 N 5 A$ & $A$ & $3 N 13 A$ & 514 & $3 / 16$ & $13 / 16$ & 0 & 1 \\
\hline $5 N 3 A$ & $A$ & $5 \mathrm{~N} 11 \mathrm{~A}$ & 1234 & $5 / 16$ & $11 / 16$ & 0 & 1 \\
\hline $3 N 5 A$ & $\mathrm{~N}$ & $11 \mathrm{~N} 5 \mathrm{~A}$ & 13056 & $11 / 16$ & $5 / 16$ & 1 & 0 \\
\hline $5 N 3 A$ & $\mathrm{~N}$ & $13 N 3 A$ & 906 & $13 / 16$ & $3 / 16$ & 1 & 0 \\
\hline 11 N5A & $A$ & 11 N32A & 315 & $11 / 32$ & $21 / 32$ & 0 & 1 \\
\hline 11N5A & $\mathrm{N}$ & 27N5A & 123 & $27 / 32$ & $5 / 32$ & 1 & 0 \\
\hline A & $A$ & $A$ & 12724 & 0 & 1 & 0 & 1 \\
\hline
\end{tabular}

Os valores nos grupos genéticos representam a porção de cada raça na constituição decada grupo, por exemplo, $1 \mathrm{~N} 3 \mathrm{~A}=1 / 4$ Nelore $+3 / 4$ Angus; $\mathrm{N}=$ Nelore; $\mathrm{A}=$ Angus.

grupo de contemporâneos, como variável classificatória, e como co-variáveis, efeitos linear e quadrático da idade da vaca ao parto (IPV) e da idade do animal ao sobreano, efeitos lineares aditivos diretos e maternos e da heterozigose individual.

As variáveis CS, PS, MS e GDS, em função dos efeitos de ambiente, foram também analisadas por meio da seguinte equação de regressão:

$$
\hat{y}=b_{0}+b_{1} x+b_{2} x^{2}
$$

em que:

$\mathrm{b}_{0}=$ intercepto;

$b_{1}$ e $b_{2}=$ coeficientes de regressão linear e quadrático, respectivamente;

$\mathrm{X}=$ efeito de ambiente observado (IPV, IDS).

O intercepto $\left(\mathrm{b}_{0}\right)$ foi estimado como:

$$
\mathrm{b}_{0}=\mu+\mathrm{b}_{1} \overline{\mathrm{x}}+\mathrm{b}_{2} \overline{\mathrm{x}}^{2}
$$

em que:

$\mu=$ média geral estimada pelo modelo;

$b_{1}$ e $b_{2}=$ coeficientes de regressão linear e quadrático, respectivamente;

$\overline{\mathrm{X}}=$ média ponderada do efeito de ambiente estimado (IPV, IDS);

$\overline{\mathrm{X}}^{2}=$ média ponderada do quadrado do efeito de ambiente estimado (IPV, IDS).

Dessa forma, a equação de regressão (1) pode ser representada por:

$$
\hat{y}=\mu+b_{1} \bar{x}+b_{2} \bar{x}^{2}+b_{1} x+b_{2} x^{2}
$$

As expressões das variáveis CS, PS, MS e GDS, em função dos efeitos genéticos (AD, AM e HI), foram analisados considerando apenas os efeitos lineares.

\section{RESULTADOSEDISCUSSÃO}

Os valores observados para as estatís- 
Tabela II. Estatísticas descritivas dos escores de conformação (CS), precocidade (PS) e musculatura (MS) ao sobreano e do ganho médio diário de peso da desmama ao sobreano (GDS), de bovinos formadores da raça Brangus. (Descriptive statistics of conformation scores (CS), early finishing (PS) and muscling (MS) at yearling and average daily gain from weaning to yearling (GDS) for bovines forming Brangus cattle).

\begin{tabular}{lccccccc}
\hline & N & Média & Moda & Mediana & Desvio padrão & Amplitude & CV (\%) \\
\hline CS & 24531 & 3,46 & 3 & 4 & 0,93 & $1-5$ & 26,88 \\
PS & 21166 & 3,44 & 3 & 3 & 0,87 & $1-5$ & 25,34 \\
MS & 24006 & 3,41 & 3 & 3 & 0,90 & $1-5$ & 26,39 \\
GDS (kg/dia) & 25419 & 0,21 & 0,20 & 0,17 & 0,08 & $0,05-0,75$ & 36,25 \\
\hline
\end{tabular}

$\mathrm{N}=$ número de observações; $\mathrm{CV}=$ coeficiente de variação.

ticas descritivas dos escores de CS, PS, MS e para GDS (tabela II) estão de acordo com o esperado, uma vez que os escores foram atribuídos em relação ao lote que os animais se encontravam e o animal tomado como médio recebeu escore três; enquanto que o ganho de peso na pós-desmama é normalmente baixo, pois nesse período ocorre o estresse da desmama e com o animal atingindo a maturidade fisiológica, a deposição muscular diminui, começando, então, a depositar gordura, que requer mais energia.

A idade da vaca ao parto (IVP) apresentou efeito linear e quadrático $(\mathrm{p}<0,01)$ sobre GDS e somente linear para PS (tabela III). Esse resultado pode ser interpretado como um efeito residual dessa fonte de variação, pois o desempenho do animal no período pós-desmama, possivelmente está mais ligado à expressão do seu próprio potencial genético para crescimento. Pons et al. (1989), trabalhando com escore de conformação (C) a um ano de idade em bovinos da raça Hereford, também observaram efeito não significativo da idade da vaca sobre C.

As curvas de regressão de PS e GDS, em função da IVP (figura 1), cujos coeficientes são apresentados na tabela IV, mostraram que os maiores escores visuais de PS foram atribuídos a filhos de vacas que pariram em torno dos 13 anos de idade, para em seguida diminuírem. Isto pode ser explicado pelo
Tabela III. Resumo da análise de variância (valores de F e quadrado médio do resíduo) para os escores de conformação (CS), precocidade (PS), musculatura (MS) ao sobreano e ganho médio de peso da desmama ao sobreano (GDS), de bovinos formadores da raça Brangus. (Summary of variance analysis) ( $F$ values and residual mean square) for conformation scores (CS), early finishing (PS) and muscling (MS) at yearling and average daily gain from weaning to yearling (GDS) for bovines forming Brangus cattle).

\begin{tabular}{|c|c|c|c|c|}
\hline & CS & PS & MS & GDS \\
\hline GC & $6,94^{\star *}$ & $4,57^{\star \star}$ & $5,80^{\star *}$ & $0,08^{* *}$ \\
\hline$G C(n)$ & 1266 & 1097 & 1255 & 1291 \\
\hline IVP & $0,95^{\mathrm{NS}}$ & $3,11^{* *}$ & $0,95^{\mathrm{NS}}$ & $0,05^{\star *}$ \\
\hline IVP2 & $0,23^{\mathrm{NS}}$ & $1,25 \mathrm{NS}$ & $0,44^{\mathrm{NS}}$ & $0,05^{\text {** }}$ \\
\hline IDS & $10,58^{* *}$ & $10,47^{\star *}$ & $14,93^{* *}$ & $0,03^{* *}$ \\
\hline IDS2 & $2,71^{* *}$ & $2,59^{\mathrm{NS}}$ & $5,17^{\star *}$ & $0,007^{N S}$ \\
\hline$A D$ & $1,41^{\mathrm{NS}}$ & $3,80^{* *}$ & $0,18^{\mathrm{NS}}$ & $0,002^{\mathrm{NS}}$ \\
\hline AM & $0,13^{\mathrm{NS}}$ & $2,75^{\mathrm{NS}}$ & $3,31^{* *}$ & $0,0001^{\mathrm{NS}}$ \\
\hline $\mathrm{HI}$ & $41,24^{* *}$ & $26,15^{* *}$ & $38,02^{* *}$ & $0,26^{* *}$ \\
\hline Resíduo & 0,689 & 0,724 & 0,712 & 0,036 \\
\hline $\mathrm{R}^{2}(\%)$ & 47 & 34 & 40 & 78 \\
\hline CV (\%) & 19,91 & 21,00 & 20,87 & 17,39 \\
\hline
\end{tabular}

${ }^{* *} \mathrm{p}<0,01 ; \mathrm{NS}=$ não significativo; $\mathrm{GC}=$ grupo de contemporâneos; IVP= idade da vaca ao parto linear; VP2 = idade da vaca ao parto quadrática; IDS= idade do animal ao sobreano linear; IDS2= idade do animal ao sobreano quadrática; $A D=$ aditivo direto linear; $\mathrm{AM}=$ aditivo materno linear; $\mathrm{HI}=$ heterozigose individual linear; $R^{2}=$ coeficiente de determinação; $C V=$ coeficiente de variação. 


\section{QUEIROZ, OLIVEIRA, COSTAEFRIES}
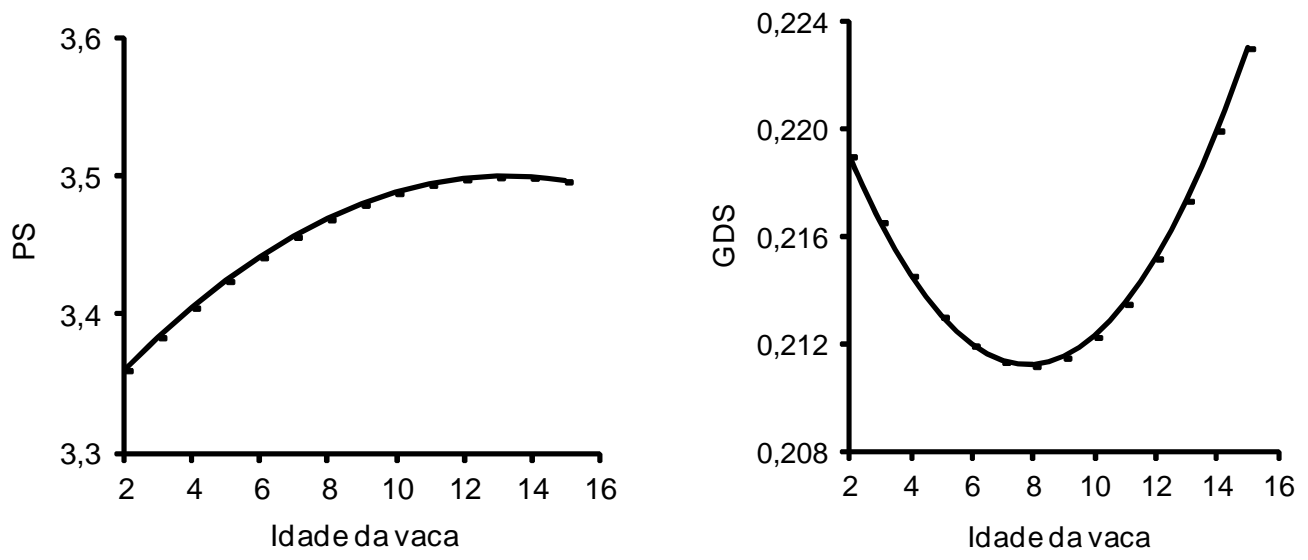

Figura 1. Valores estimados para precocidade ao sobreano (PS) e ganho médio diário de peso da desmama ao sobreano (GDS) em função da idade da vaca (IVP), para bovinos formadores da raça Brangus. (Estimates for early finishing at yearling (PS) and average daily weight gain from weaning to yearling (GDS) as a function of age of dam at calving (IVP) for bovines forming Brangus cattle).

fato de vacas jovens e vacas mais velhas, terem produção de leite inferior a de vacas com idade madura e desmamarem bezerros com menor desenvolvimento, e por conseqüência apresentarem menor desenvolvimento ao sobreano e com menores escores de PS. A precocidade de terminação, que se refere à capacidade do animal apresentar grau de acabamento mínimo de carcaça,

Tabela IV. Estimativas dos coeficientes de regressão ( $r$ ) dos escores visuais de precocidade(PS) ao sobreano e ganho médio diário de peso da desmama ao sobreano (GDS) em função da idade da vaca ao parto e do intercepto, para bovinos formadores da raça Brangus. (Regression coefficient ( $r$ ) estimates for visual scores of early finishing (PS) and average daily gain from weaning to yearling (GDS) as a function of age of dam at calving and the intercept for bovines forming Brangus cattle).

\begin{tabular}{lcccc}
\hline & $\begin{array}{c}\text { Intercepto } \\
\mathrm{b}_{0}\end{array}$ & $\mathrm{~b}_{1}$ & $\mathrm{~b}$ \\
\hline PS & 3,3063 & 0,0292 & $-0,0011$ \\
GDS & 0,2252 & $-0,0036$ & 0,0002 \\
\hline
\end{tabular}

pode estar associada ao fato dos bezerros mais desenvolvidos, filhos de vacas maduras, estarem começando a depositar gordura antes dos animais filhos de vacas mais jovens ou mais velhas, que desmamaram bezerros menos desenvolvidos.

A variação do GDS em função da idade da vaca ao parto mostrou que vacas entre sete e nove anos de idade produziram bezerros com os menores ganhos de peso da desmama ao sobreano, enquanto que, as vacas mais jovens ou mais velhas, produziram bezerros com os maiores ganhos (figura 1). Os resultados observados neste estudo podem estar indicando crescimento compensatório dos bezerros no período pósdesmama, ou seja, bezerros filhos de vacas jovens ou mais velhas, que provavelmente produziram menos leite, ganharam mais peso nesse período. Quando o crescimento do animal é retardado em conseqüência de uma subnutrição, ele é capaz de se recuperar quando cessa a restrição alimentar, crescendo, em geral, a taxas mais aceleradas. A mesma tendência foi relatada Muniz e Queiroz (1999).

Os escores CS e MS apresentaram efeito

Archivos de zootecnia vol. 62, núm. 237, p. 116. 
quadrático da idade do animal (IDS2), enquanto que este efeito foi linearmente significativo $(\mathrm{p}<0,01)$ para o escore de PS e GDS (tabela III). Muniz e Queiroz (1999) e Sarmento et al. (2003), também relataram efeito significativo de IDS sobre GDS, respectivamente, em bovinos cruzados e da raça Nelore. Os coeficientes de regressão $\left(b_{1}\right.$ e $\left.b_{2}\right)$ utilizados para estimar CS, PS e MS em função da idade do animal foram, respectivamente, positivos e negativos, e o contrário para GDS (tabela V). Consequentemente, as curvas de regressão (figura 2) mostraram que os escores visuais ao sobreano aumentaram com a idade do animal, sendo que os animais mais jovens apresentaram menor desenvolvimento corporal, quando comparados aos mais velhos, que receberam os maiores escores. O contrário ocorreu, entretanto, com GDS, que diminuiu com o aumento da idade do animal (figura 2). À medida que o animal cresce e se desenvolve, ocorrem mudanças morfofisiológicas que são resultantes, em grande

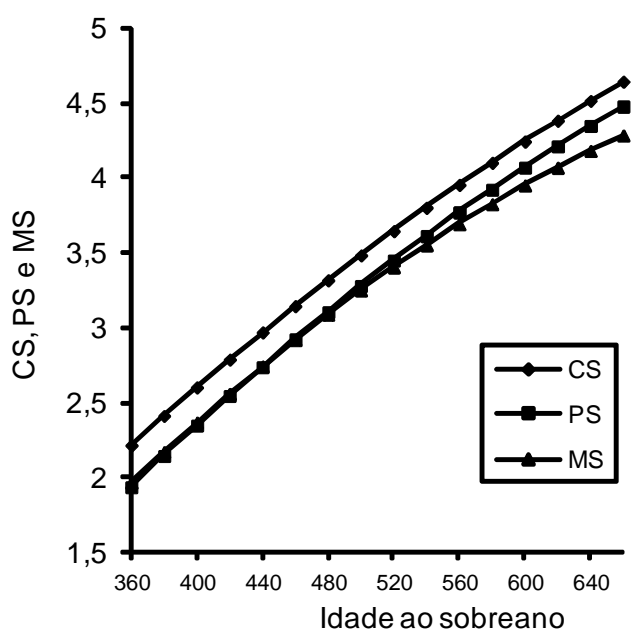

Tabela $\boldsymbol{V}$. Estimativas dos coeficientes de regressão $(r)$ dos escores visuais de conformação (CS), precocidade (PS), musculatura (MS) ao sobreano e ganho médio diário de peso da desmama ao sobreano (GDS), em função da idade do bezerro, e do intercepto, para bovinos formadores da raça Brangus. (Regression coefficient estimates for visual scores of conformation (CS), early finishing (PS), muscling (MS) at yearling and average daily gain from weaning to yearling (GDS), according to the age of the calf and the intercept for bovines forming Brangus cattle).

\begin{tabular}{lcrc}
\hline & $\begin{array}{c}\text { Intercepto } \\
b_{0}\end{array}$ & $b_{1}$ & $b_{2}$ \\
\hline CS & $-2,1134$ & 0,0142 & $-0,000006$ \\
PS & $-2,7674$ & 0,0156 & $-0,000007$ \\
MS & $-2,9474$ & 0,0169 & $-0,000009$ \\
GDS & 0,5258 & $-0,0007$ & 0,0000003 \\
\hline
\end{tabular}

parte, das ações hormonais. Após o nascimento, o indivíduo apresenta uma fase de crescimento rápido quando o tecido de

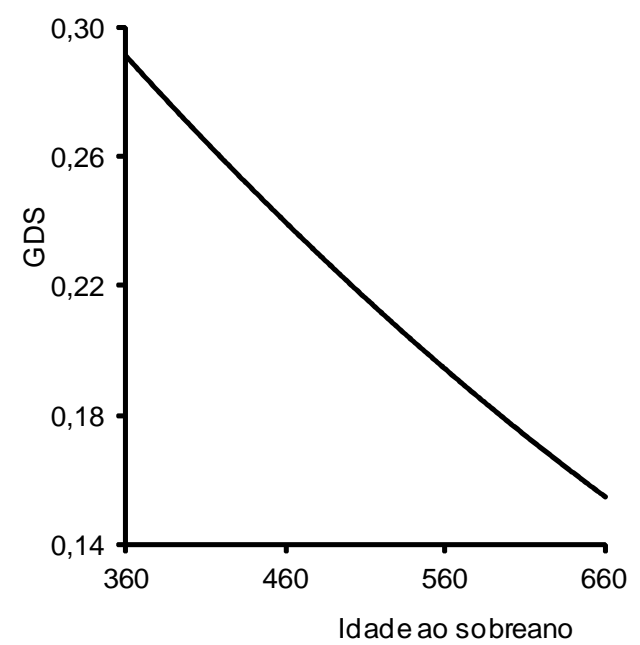

Figura 2. Valores estimados para conformação (CS), precocidade (PS), musculatura (MS) ao sobreano e ganho médio diário de peso da desmama ao sobreano (GDS), em função da idade do animal ao sobreano (IDS), para bovinos formadores da raça Brangus. (Estimates for conformation (CS), early finishing (PS) and muscling (DM) at yearling and average daily weight gain from weaning to yearling (GDS), as a function of age of the animal at yearling (IDS) for bovines forming Brangus cattle). 


\section{QUEIROZ, OLIVEIF}

maior deposição é o tecido muscular. Após atingir a puberdade, de modo geral, há aumento na deposição de tecido adiposo, e proporcional redução tanto de ossos quanto de músculos, refletindo em pior conversão alimentar, ou seja, o animal necessita de mais alimento para ganhar peso, resultando em menores ganhos de peso (Cervieri et al., 2005). Esse efeito pode ter ocorrido ainda, devido à pesagem na pós-desmama estar sendo realizada muito próxima da pesagem na desmama para alguns animais e para outros com intervalos maiores, de até 300 dias.

O efeito do grupo de contemporâneos (GC) influenciou significativamente $(\mathrm{p}<0,01)$ todas as características estudadas (tabela III), que é um resultado esperado uma vez que os fatores ambientais contidos no mesmo reconhecidamente afetam o desempenho dos animais.

Com relação aos efeitos genéticos incluídos nos modelos, o efeito genético aditivo direto (AD), que neste estudo expressa a fração Nelore do produto, foi significativo $(\mathrm{p}<0,01)$ apenas para $\mathrm{PS}$, enquanto que o aditivo materno (AM) foi significativo $(\mathrm{p}<0,01)$ somente para MS (tabela III). Os coeficientes de regressão linear $\left(b_{1}\right)$ utilizados para estimar PS e MS em

Tabela VI. Estimativas dos coeficientes de regressão $(r)$ dos escores visuais de precocidade (PS) e musculatura (MS) ao sobreano, em função dos efeitos genéticos aditivos diretos $(A D)$ e maternos (AM), e do intercepto, para bovinos formadores da raça Brangus. (Regression coefficient estimates for visual scores of early finishing (PS) and muscling (MS) at yearling according to the additive genetic (AD) and maternal (AM) effects and the intercept for bovines forming Brangus cattle).

\begin{tabular}{lccc}
\hline & Intercepto & $\left(\mathrm{b}_{0}\right)$ & $\mathrm{r}\left(\mathrm{b}_{1}\right)$ \\
\hline PS & 3,5952 & AD & $-0,3764$ \\
MS & 2,1960 & AM & 1,9036 \\
\hline
\end{tabular}

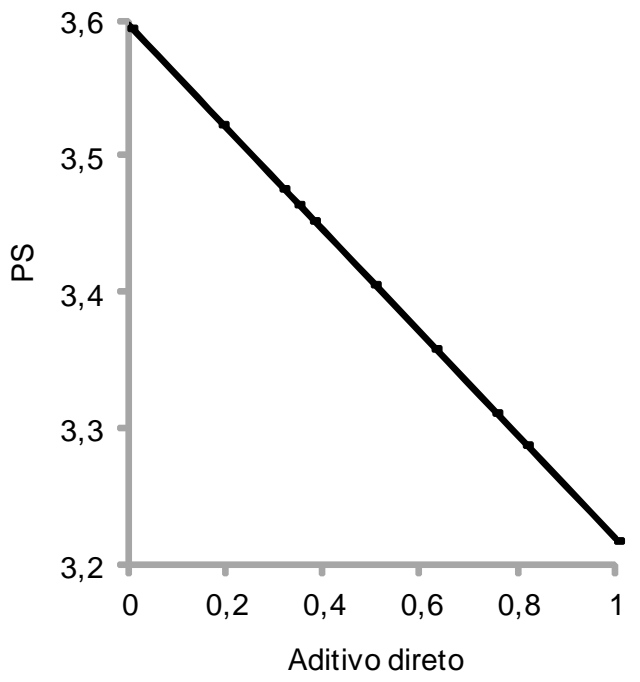

Figura 3. Valores estimados para precocidade ao sobreano (PS), em função do efeito genético aditivo direto (AD), para bovinos formadores da raça Brangus. (Estimates for early finishing (PS) at yearling as a function of the direct genetic effect (AD) for bovines forming Brangus cattle).

função dos efeitos aditivos direto e materno (tabela VI), sugerem que os escores de precocidade decresceram, em média, 0,38 , enquanto que os de musculatura cresceram, em média, 1,90, para cada unidade dos efeitos genéticos aditivos direto (AD) e materno (AM), respectivamente.

A ação gênica aditiva é aquela em que cada um dos genes que constituem o genótipo (em relação a uma característica qualquer) manifesta seu efeito no valor fenotípico do indivíduo, independente dos outros genes e alelos presentes.

$\mathrm{O}$ efeito genético aditivo direto da raça Nelore como desvio da raça Angus (figura 3), foi negativo para o escore de precocidade ao sobreano (PS). Este resultado indica que a maior proporção de genes da raça Nelore no bezerro diminuiu a estimativa de PS. O valor negativo e significativo do efeito aditivo direto para os animais da raça Nelore, 


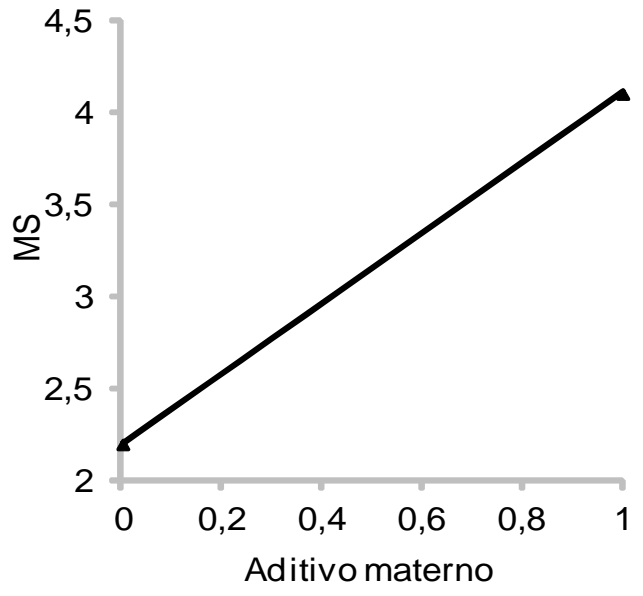

Figura 4. Valores estimados para musculatura ao sobreano (MS), em função do efeito genético aditivo materno, para bovinos formadores da raça Brangus. (Estimates for muscling at yearling (MS) as a function of the additive genetic effect for bovines forming Brangus cattle).

como desvio da raça Angus, demonstra a superioridade da raça Angus em precocidade em relação ao Zebu, que é mais adaptado às condiçõoes brasileiras, porém mais tardio.

Nesse estudo, como foram eliminados animais que tinham informações da fração zebuína dos avôs e avós maternos diferente de zero, o conjunto de dados referiu-se apenas a vacas puras Angus e Nelore.

O efeito aditivo materno foi significativo $(\mathrm{p}<0,01)$ somente para o escore MS (tabela III), sendo que os animais avaliados visualmente para esse escore apresentaram tendência positiva do efeito aditivo materno da raça Nelore, como desvio da raça Angus (figura 4), o que se pode supor que a maior percentagem de genes da raça Nelore na vaca foi favorável ao desenvolvimento do animal. Como esse efeito indica a diferença entre as duas raças, quanto à habilidade materna, pode-se supor que bezerros F1, filhos de vacas da raça Nelore apresentaram melhores escores de MS que os filhos de vacas Angus. Isso pode ser atribuído, provavelmente, ao fato das vacas da raça Nelore, ser geneticamente superiores, para musculatura, às vacas Angus.

$\mathrm{O}$ efeito da heterozigose individual foi positivo e significativo $(\mathrm{p}<0,01)$ para todas as características estudadas (tabela III), indicando que, quanto maior a heterozigose do animal, melhor o seu desempenho. Isto sugere que este efeito deve ser considerado nas avaliações genéticas de animais cruzados para características de crescimento e escores visuais, juntamente com os efeitos ambientais.

Os coeficientes de regressão $\left(b_{1}\right)$ utilizados para estimar CS, PS, MS e GDS em função da heterozigose individual (tabela VII) foram positivos, o que indica que os desempenhos dos animais em relação a essas características melhoraram com a heterosigose, sendo que os animais $\mathrm{F} 1$, ou seja, com heterozigose individual igual a 1 , foram superiores (figura 5). Os resultados de cruzamentos empregando-se raças européias e indianas, como se verificou nos animais utilizados no presente trabalho,

Tabela VII. Estimativas dos coeficientes de regressão $(r)$ dos escores visuais de conformação (CS), precocidade (PS), musculatura (MS) ao sobreano e ganho médio diário da desmama ao sobreano (GDS), em função da heterozigose individual, e do intercepto, para bovinos formadores da raça Brangus. (Regression coefficient estimates for visual scores of conformation (CS), early finishing (PS) and muscling (MS) at yearling and average daily gain from weaning to yearling (GDS), according to the individual heterozygosity, and the intercept bovines forming Brangus cattle).

\begin{tabular}{lcc}
\hline & Intercepto $\left(b_{0}\right)$ & $r\left(b_{1}\right)$ \\
\hline CS & 3,1416 & 0,5166 \\
PS & 3,1827 & 0,4213 \\
MS & 3,0985 & 0,4959 \\
GDS & 0,1865 & 0,0415 \\
\hline
\end{tabular}




\section{QUEIROZ, OLIVEIRA, COSTA EFRIES}
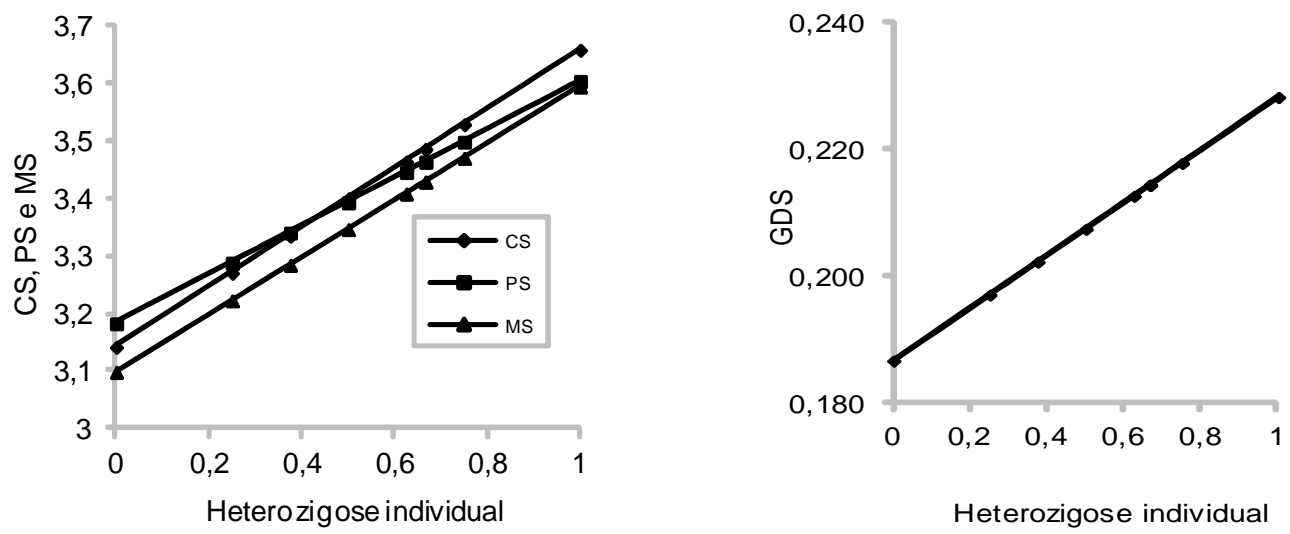

Figura 5. Valores estimados para conformação (CS), precocidade (PS), musculatura (MS) ao sobreano e ganho médio diário de peso da desmama ao sobreano (GDS), em função da heterozigose individual, para bovinos formadores da raça Brangus. (Estimates for conformation (CS), early finishing (PS) and muscling (DS) at yearling and average daily weight gain from weaning to yearling (GDS), as a function of the individual heterozygosity, for bovines forming Brangus cattle).

mostraram melhor desempenho dos animais cruzados em relação aos puros, pela expressão da heterose, conforme já relatado nos trabalhos de Euclides Filho (1996), Trematore et al. (1998) e Muniz e Queiroz (1999).

A heterose indica a superioridade de indivíduos cruzados, em relação à média dos pais puros, para uma determinada característica. Os sistemas de cruzamentos são utilizados para promover a heterose e a complementaridade das características desejáveis das raças envolvidas. O uso das raças sintéticas, formadas por cruzamentos sistemáticos entre duas raças, como é o caso da raça Brangus, utiliza de efeitos favoráveis da heterose, para características de baixa herdabilidade e de resposta lenta a seleção individual, somando, em um mesmo indivíduo, atributos econômicos desejáveis em várias raças (complementaridade), como a resistência ao estresse ambiental presente nos zebuínos com a precocidade e melhor acabamento de carcaça encontrada nos taurinos.

\section{CONCLUSÕES}

Os efeitos de idade da vaca ao parto e do animal, da fração zebuína do produto (aditivo direto) e da heterozigose individual (não aditivo), revelaram ser importantes fontes de variação nos escores de conformação, precocidade e musculatura ao sobreano e sobre o ganho diário de peso da desmama ao sobreano de bovinos Brangus. O controle dos dois primeiros efeitos deve ser levado em conta nas avaliações genéticas e dos últimos nos critérios de seleção desses bovinos.

\section{AGRADECIMENTO}

À Gensys Consultores Associados S/C Ltda. pela cessão dos dados e ao CNPq pela concessão de bolsa de pesquisa aos autores.

\section{BIBLIOGRAFIA}

ANUALPEC. 2010. Anuário da Pecuária Brasileira. FNP Consultoria \& Comércio. São Paulo. 360 pp. 


\section{EFEITOS AMBIENTAIS E GENÉTICOS SOBRE ESCORES VISUAIS E GANHO EM PESO}

notícias> (26/04/2011).

Bocchi, A.L.; Teixeira, R.A. e Albuquerque, L.G. 2004. Idade da vaca e mês de nascimento sobre o peso ao desmame de bezerros nelore nas diferentes regiões brasileiras. Rev Bras Zootecn, 26: 475-482.

Campos, L.T. e Cardoso, F.F. 1995. Programa de melhoramento de bovinos de carne: manual do usuário. Associação Nacional de Criadores (Herd Book Collares). Pelotas, RS. 32 pp.

Cervieri, R.C.; Arrigoni, M.B.; Chardulo, L.A.L.; Silveira, A.C.; Oliveira, H.N. e Martins C.L. 2005. Peso vivo final, ganho de peso, características de carcaça e concentrações plasmáticas de IGF-I e hormônios tireoideanos de bezerros mestiços Angus-Nelore recebendo somatropina bovina recombinante (rbST) até a desmama. Rev Bras Zootecn, 34: 2009-2019.

Costa, G.Z.; Queiroz, S.A.; Oliveira, J.A. e Fries, L.A. 2008. Estimativas de parâmetros genéticos e fenotípicos de escores visuais e de ganho médio de peso do nascimento a desmama de bovinos formadores da raça Brangus. Ars Vet, 24: 172-176.

Euclides Filho, K. 1996. O melhoramento genético e os cruzamentos em bovinos de corte. Campo Grande, MS. 35 pp.

Fries, L.A. 1996. Uso de escores visuais em programas de seleção para produtividade em gado de corte. Seminário Nacional - Revisão de
Critérios de Julgamento e Seleção em Gado de Corte. Anais... Associação Brasileira dos Criadores de Zebu. Uberaba, MG. pp. 1-6.

Maciel, R.A. 2000. Introdução à raça Brangus no Brasil. Pecuária de corte, 12: 36-39.

Muniz, C.A.S.D. e Queiroz, S.A. 1999. Avaliação de características de crescimento pósdesmama de animais Nelore e cruzados no Estado do Mato Grosso do Sul. Rev Bras Zootecn, 28: 713-720.

Pons, S.B.; Milagres, J.C. e Fontes, C.A.A. 1989. Efeitos de fatores genéticos e de ambiente sobre o crescimento e o escore de conformação em bovinos Hereford no Rio Grande do Sul. II Peso e escore de conformação a um ano de idade. Rev Bras Zootecn, 18: 402-409.

Sarmento, J.L.R.; Pimenta Filho, E.C.; Ribeiro, M.N e Martins Filho, R. 2003. Efeitos ambientais e genéticos sobre o ganho em peso diário de bovinos Nelore no Estado da Paraíba. Rev Bras Zootecn, 32: 325-330.

Teixeira, R.A. e Albuquerque, L.G. 2003. Efeitos ambientais que afetam o ganho de peso prédesmama em Angus. Rev Bras Zootecn, 32: 887-890.

Trematore, R.L.; Alencar, M.M.; Barbosa, P.F.; Oliveira, J.A.L. e Almeida, M.A. 1998. Estimativas de efeitos aditivos e heteróticos para características de crescimento pré-desmama em bovinos Charolês-Nelore. Rev Bras Zootecn, 27: 87-94. 